\title{
Analysis of Recoverable Exhaust Energy from a Light-Duty Gasoline Engine
}

Tianyou Wang ${ }^{1}$, Yajun Zhang ${ }^{1}$, Zhang $\mathrm{Jie}^{1}$, Gequn Shu ${ }^{1}$, Zhijun Peng ${ }^{2 *}$

1) State Key Laboratory of Engines, Tianjin University, China

2) Department of Engineering and Design, University of Sussex, UK

* Corresponding author

\begin{abstract}
While EER (Exhaust Energy Recovery) has been widely pursued for improving the total efficiency and reducing $\mathrm{CO}_{2}$ emissions of internal combustion engines, the maximum regenerated power from the exhaust energy has been proposed and calculated in terms of endoreversible cycle. In this paper, based on the experimental data of an EER system installed on a light duty gasoline engine, the exhaust energy and maximum recoverable energy were analysed, by defining a new parameter of the recoverable exhaust energy efficiency (the fraction of maximum recoverable exhaust energy in the total fuel energy) for reflecting the available energy of exhaust energy in all mentioned engine operating conditions. Combining those experimental and modelling data, results show the engine exhaust gases temperature increases with both of the speed and load in the overall operating conditions of vehicle, ranging among $400^{\circ} \mathrm{C}$ and $850^{\circ} \mathrm{C}$. With water as the working fluid for the EER system, the recoverable exhaust energy efficiency ranges among 5\% and $21 \%$ under different engine operating condition and it could be up to $19 \%$ in a rather wide load range under general engine operating speed.
\end{abstract}

Keywords : internal combustion engine, exhaust energy recovery (EER), recoverable exhaust energy efficiency 


\section{INTRODUCTION}

In recognition of the need to further reduce vehicle exhaust emissions and the greenhouse gas $\mathrm{CO} 2$ as the oil price has kept roaring up, there has been an increasing interest in the development of cleaner and more efficient energy saving vehicle powertrain. It is thought future sustainable vehicle powertrain developments beyond the next decade are likely to be focused on four topics [1]: emission legislation and control, new fuels, improved combustion and a range of advanced concepts for energy saving. And among the various advanced concepts, EER (Exhaust Energy Recovery) for IC engine has been proved to not just bring measurable advantages for improving fuel consumption but also increase engine power output (power density) or downsizing, further reducing $\mathrm{CO} 2$ and other harmful exhaust emissions correspondingly. It was predicted by Vazaquez et al. [2] that if $6 \%$ of the heat contained in the exhaust gases were converted to electric power, $10 \%$ reduction of fuel consumption can be achieved.

Early researches on EER have investigated the basic concepts, problems and expected improvements for such a system. An example could be found from the research conducted by Chammas and Clodic [3], who presented the advantages offered by a Rankine system designed for hybrid vehicles, up to $18 \%$ fuel economy improvement could be achieved when water was used to recover the exhaust heat.

More recently reports [4] showed how further investigation of the technology and architectures are possible. For instance, Teng et al. carried out a series of experiments [5-7] on heavy-duty diesel engines to explore the potential of EER, with hybrid energy systems combined the exhaust system with the charge air cooler and EGR cooler(s). Their results show that up to $20 \%$ increase in the engine power and 5\% improvement in fuel savings over the ESC 13-mode test could be achieved by the EER system. Ringler et al. [8] selected two basic EER configurations (one just with exhaust gas only and another with exhaust gas plus coolant) from numerous illustrated Rankine cycle layouts for a detailed evaluation of heat recovery based on a four-cylinder IC engine. Their experimental 
works demonstrated that waste heat recovery can produce an additional power output of about $10 \%$ at typical highway cruising speeds. Weerasinghe et al. [9] identified the substantial potential of EER for IC engines via two most promising and technically viable technologies: turbo-compounding and exhaust heat secondary fluid power cycles. Their results revealed that the two EER technologies would contribute more power output in the order of $4.1-7.8 \%$ and fuel savings by $2-22 \%$. Various researches have underlined the interest in light to heavy duty vehicle applications and suggest that fuel economy improvements of up to $20 \%$ can be expected from EER.

In this paper, the study which has been focused on the exhaust energy from a gasoline engine with the objective of exploring the available recoverable energy in exhaust gas is presented. While the exhaust temperature and gas flow rate vary with engine operating conditions, the available exhaust energy for EER and its characteristic under different engine operating conditions would be understood. Then the optimal operating areas for utilizing the exhaust energy could be identified. In the current study, a four-cylinder light-duty gasoline engine was employed for experimental recoverable exhaust energy.

\section{PARAMETER DEFINITION AND MODEL DESCRIPTION}

The EER system which will be used in the present research is based on Rankine cycle and physically it comprises four main components: an evaporator/heat exchanger, an expander, a condenser and a pump. The layout of the system is shown in Figure 1 and its temperature-entropy diagram is presented in Figure 2. 


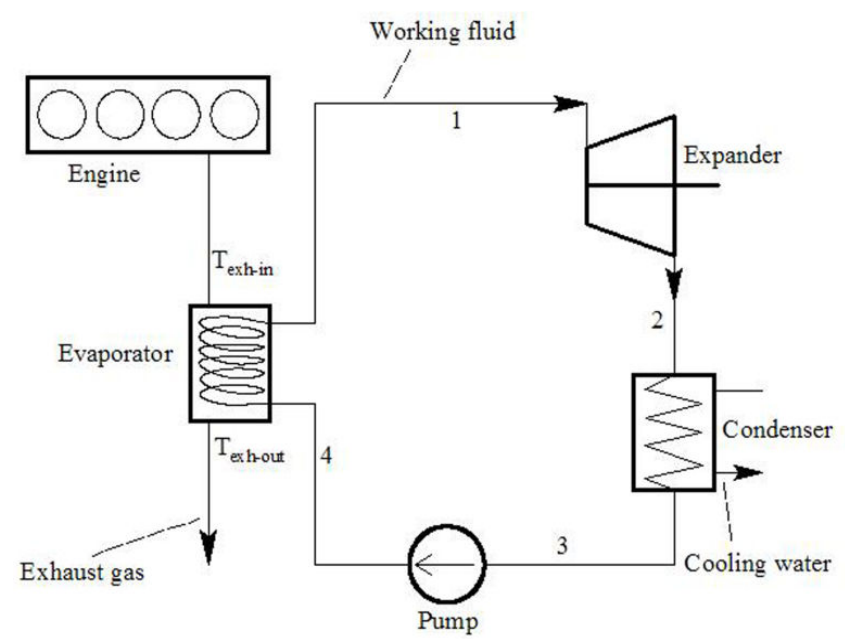

Figure 1 Layout of the EER system

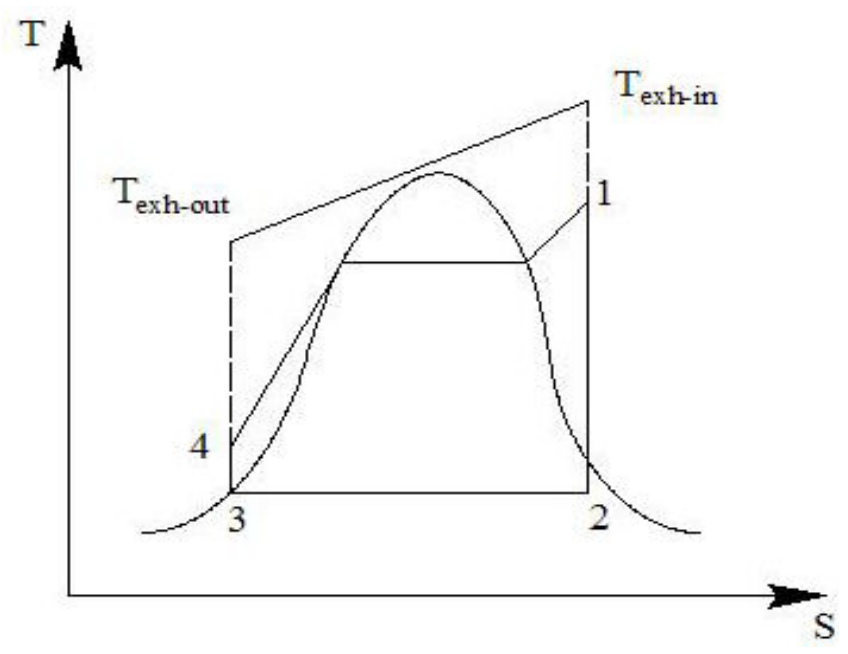

Figure 2 T-S diagram of the EER system

With the evaporator/heat changer, the working fluid is superheated by absorbing thermal energy provided from the exhaust gas. Flowing out from the evaporator as high temperature steam, the working fluid is driving the expander to produce useful work. Then the waste steam from the expander will be cooled down through the condenser to return to liquid phase. In the next step, the working fluid is run to maintain the circulation.

For most internal combustion engines, there is approximately $20 \sim 40 \%$ of total fuel energy which is dissipated through exhaust gas, with the major part as sensible enthalpy due to high exhaust temperature and minor part as chemical enthalpy due to incomplete combustion. To evaluate energy amount in the exhaust gas, it is necessary to obtain the thermo-physical parameters of exhaust gases. Considering currently all diesel engines and most gasoline engines during dominant operating period are driven with lean combustion condition, an assumption of complete in-cylinder combustion would be used for the following analysis while the focus of this research work is on the thermal energy recovery of exhaust gas. Then small amounts of incomplete combustion products such as $\mathrm{CO}$ and unburnt hydrocarbon and NOx emission components could be ignored and the compositions of exhaust gases could be considered as the mixture of $\mathrm{CO}_{2}, \mathrm{H}_{2} \mathrm{O}, \mathrm{N}_{2}$ and $\mathrm{O}_{2}$. 
Provided that the stoichiometric air-fuel ratio in the gasoline combustion is $a_{0}$, and the actual one is $\alpha$, the molar fractions for $\mathrm{N}_{2}$ and $\mathrm{O}_{2}$ in the air mixture is $k_{N 2}$ and $k_{O 2}$, respectively. While the atom numbers of carbon and hydrogen in the hydrocarbon fuel molecular are $\theta_{C}$ and $\theta_{H}$, respectively, the molar fractions of compositions in the exhaust gases could be obtained by the following equations, respectively.

$$
\begin{aligned}
& \phi_{N 2}=\frac{a k_{N 2}}{1+a+a_{0} k_{O 2}-\theta_{H} / 2} \\
& \phi_{O 2}=\frac{\left(a-a_{0)} k_{O 2}\right.}{1+a+a_{0} k_{O 2}-\theta_{H} / 2} \\
& \phi_{C O 2}=\frac{\theta_{C}}{1+a+a_{0} k_{O 2}-\theta_{H} / 2} \\
& \phi_{H 2 O}=\frac{\theta_{H} / 2}{1+a+a_{0} k_{O 2}-\theta_{H} / 2}
\end{aligned}
$$

Considering the above four compositions are all ideal gases, their constant pressure heat capacity $C_{p, i}$ could be achieved by the empirical formulas $[10]$ :

$$
C_{p, i}=\left(c_{0}+c_{1} T+c_{2} T^{2}+c_{3} T^{3}+c_{4} T^{4}\right) R
$$

Given the exhaust gases ideal condition, the specific enthalpy could be calculated by:

$$
h=\sum_{i} \omega_{1} M_{i} h_{i} \times 10^{-3}
$$

where, $\omega_{i} 、 M_{i}$ and $h_{i}$ are the molar fraction molar mass and specific enthalpy for each composition. And the latter could be expressed by:

$$
h_{i}=h_{0}+\int_{T_{0}}^{T} C_{p, i} d T
$$

Combined the equations (1) to (4), the specific enthalpy of exhaust gases can be achieved. 
It should be noted the above formulae can only be selected for calculating the specific enthalpy of exhaust gases when all thermal recovery process did not involve steam condensation of exhaust gas and there is only the sensible heat of the exhaust gases which is absorbed by the thermal recovery system. When the steam condensing heat should be included if there is phase change of exhaust gas via the evaporator, the exhaust specific enthalpy was obtained from NIST-Refprop database.

Then, the exhaust heat $Q_{e x h}$ and its fraction in the total fuel energy could be given by:

$$
\begin{aligned}
& Q_{\text {exh }}=\left(h_{\text {exh }}-h_{\text {out }}\right) m_{\text {exh }} \\
& \eta_{\text {exh }}=\frac{Q_{\text {exh }}}{h_{f} m_{f}}
\end{aligned}
$$

where, $m_{e x h}$ and $m_{f}$ are the mass flow rate of exhaust gas and fuel, respectively, $h_{\text {exh }}$ and $h_{f}$ are the corresponding exhaust gas enthalpies, and the low heating value of fuel.

For estimating the recoverable energy from exhaust sensible heat, the Chambadal-Novikov efficiency or Curzon-Ahlborn efficiency [11] shown in the following formula is employed in the current calculation.

$$
\eta_{m, p}=1-\sqrt{\frac{T_{L, i n}}{T_{H, i n}}}
$$

where $T_{L, \text { in }}$ and $T_{H, \text { in }}$ represent the inlet temperatures of the cold and hot heat sinks with finite thermal capacitance, i.e. the exhaust temperature at the heat exchanger exit $T_{\text {out }}$ and the exhaust temperature $T_{\text {exh,in }}$ for the calculation of the maximum convertible energy of exhaust.

The Chambadal-Novikov efficiency or Curzon-Ahlborn efficiency is for a semi-ideal engine operating at maximum power output in which heat transfer is irreversible but other components are ideal. It gives an upper bound on energy that can be derived from a real process that is lower than 
that predicted by Carnot for a Carnot cycle, and accommodates the exergy destruction occurring as heat is transferred irreversibly [12].

Although sometime the Carnot efficiency is used to calculate the maximum recoverable energy, the Chambadal-Novikov efficiency or Curzon-Ahlborn efficiency was proposed on the basis of endoreversible cycle with the target of gaining the maximum output power which is the optimal purpose for a EER system, becasure the latter one considered the temperature difference of heat (cold) source and the working fluid which would cause irreversible loss. It is also thought the Carnot efficiency would be equal to the Chambadal-Novikov efficiency or Curzon-Ahlborn when the power outputs of a Carnot heat engine reach the maximum [12]. Klein checked this expression and suggested that it gives a more realistic estimate of the efficiencies seen in real heat-power cycles than the Carnot Approach [13].

By using the Chambadal-Novikov efficiency or Curzon-Ahlborn efficiency, the maximum energy recovery from exhaust gases can be estimated as follows.

$$
Q_{e x h, r}=Q_{e x h} \eta_{m, p}
$$

Then, the exhaust recoverable energy efficiency based on the total fuel energy can be expressed as :

$$
\eta_{e x h, r}=\eta_{e x h} \eta_{m, p}
$$

The fraction of recoverable exhaust sensible heat in the total fuel energy is actually working as the recoverable energy adaptive coefficient. The coefficient is proposed in the current study for reflecting the fluctuations of exhaust temperature and recoverable exhaust energy with the engine operating conditions, and also for estimating the available energy in the exhaust gas under all mentioned engine operating conditions. 
After those above parameters were defined, simulations for estimating recoverable exhaust energy with the above EER system and for finding the optimal operating conditions of the gasoline engine to achieve the maximum power output were carried out on a MATLAB/SIMULINK platform. In the simulation model, performance parameters for those critical components are considered as follow.

The Energy balance in the evaporator could be given as:

$$
Q_{e} \eta_{h}=Q_{w}
$$

Where, $Q_{e}$ and $Q_{w}$ represent the heat provided by the exhaust gas and the heat absorbed by the working liquid, respectively. $\eta_{h}$ is the efficiency of evaporator. This formula could be further expressed by:

$$
m_{\text {exh }}\left(h_{\text {exh }}-h_{\text {out }}\right) \eta_{h}=m_{w}\left(h_{w-o u t}-h_{w-i n}\right)
$$

Where, $m_{\text {exh }} 、 h_{\text {exh-in }} 、 h_{\text {exh-out }}$ stand for the mass flow rate, inlet and outlet specific enthalpy for exhaust gases respectively, and $m_{w} 、 h_{w-\text { in }} 、 h_{w-o u t}$ are the corresponding parameters for working fluid.

The function of evaporator model is to simulate the heat transfer process in the evaporator by calculating the outlet temperature of the working fluid at given pressure and flow rate. With the assuming inlet parameters for the exhaust gases and working fluid and the sizes of the evaporator, the outlet temperature could be yielded by iterative program. Basing on the design parameters of the evaporator, the heat transferred in it could be also calculated as

$$
Q_{w}=U_{m} A \Delta T_{m}
$$

Where, $U_{m}$ represents the average heat transfer coefficient of the heat transfer process, $A$ is the overall heat transfer area of evaporator, and $\Delta T_{m}$ is the logarithmic mean temperature difference in 
the heat transfer process.

For the expander, the specific enthalpy $h_{w-o u t}$ and entropy $s_{\text {exp }}$ in the inlet of expander could be obtained with the results from the evaporator model. And the pressure $p_{\text {exp-out }}$ in the outlet of expander would be determined by condensing pressure. Assuming the working fluid's expansion process is isentropic, the specific enthalpy in the outlet of expander could be identified by $p_{\text {exp-out }}$ and $s_{\text {exp }}$. Therefore, the power output produced by the expander could be calculated as

$$
W_{\exp }=m_{w}\left(h_{\exp -o u t}-h_{w-o u t}\right) \eta_{\exp }
$$

Where, $\eta_{\exp }$ represents the expander efficiency.

In the pump, the process can be expressed with the following formula when the process is assumed as isentropic.

$$
W_{\text {pump }}=m_{w}\left(h_{\text {pump-out }}-h_{\text {pump-in }}\right) \eta_{\text {pump }}
$$

\section{TEST DESCRIPTION}

As a close loop is still under construction, the present experiment is conducted on an open Rankine cycle system which is connected with a 1.3-liter gasoline engine and the system structure is shown in Figure 3. The main specifications of the engine is listed in Table 1. In the present test, water was chosen as the working fluid. 


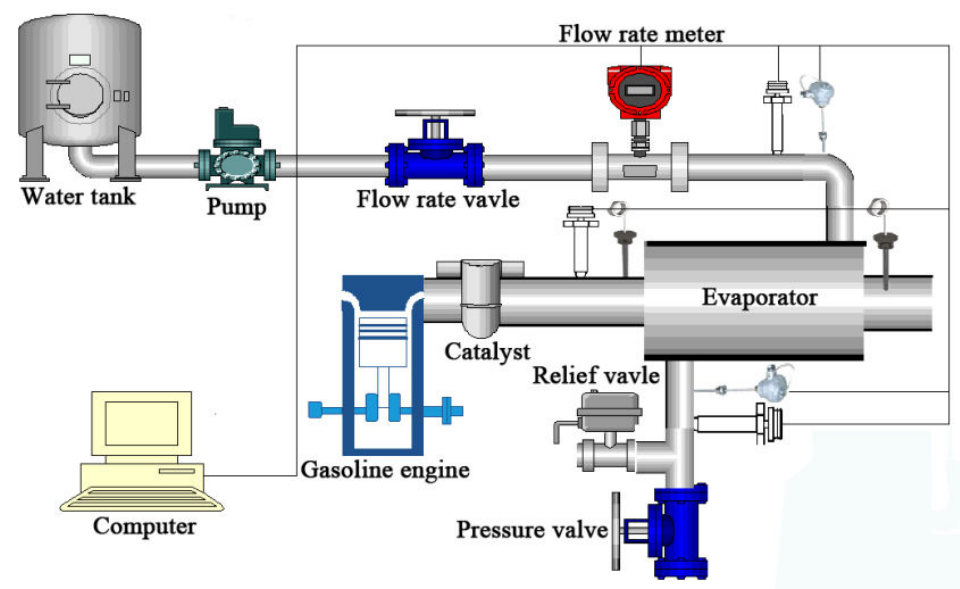

Figure 3 The open Rankine cycle system for exhaust energy recovery with a gasoline engine

Table 1 Specifications of CA4GA1 Engine

\begin{tabular}{|l|r|}
\hline Engine type & CA4GA1 \\
Number of cylinders & 4 \\
Bore $\times$ Stroke $(\mathrm{mm})$ & $73 \times 80$ \\
Displacement $(\mathrm{L})$ & 1.339 \\
Compression ratio & 10 \\
Number of valves & 16 \\
Camshaft type & DOHC \\
Rated power/speed & $67 / 6000$ \\
(kW/rpm) & \\
Maximum torque/speed & $120 / 4200$ \\
$(\mathrm{Nm} / \mathrm{rpm})$ & \\
\hline
\end{tabular}

\section{RESULTS AND DISCUSSION}

\subsection{Distribution of Exhaust Gas Temperature}

For studying EER, several parameters of air mass flow rate and exhaust gases, such as temperature, mass flow rate, would be required for the calculation of exhaust energy. In those parameters, the exhaust temperature plays a so important role, such as for the design of recovery system, the choice of working fluids and the optimization of system [14]. Therefore, in order to make full advantages 
of exhaust energy, it is necessary to have adequate information of the distribution of exhaust gases temperature under different engine operating conditions. As shown in Figure 4, it is the measured exhaust gas temperature as function of engine speed and corrected engine load (torque).

It could be found that the exhaust gases temperature depends strongly on the engine speeds and loads. Here it should be noted the actual vehicle operation normally needs the engine speed ranges from 2000 to $4000 \mathrm{rpm}$. During the mid-range of the engine load $(40-80 \mathrm{Nm})$, the corresponding exhaust gases temperature of the test engine can be $500^{\circ} \mathrm{C}$ to $700^{\circ} \mathrm{C}$, while it will be up to $850^{\circ} \mathrm{C}$ at the full load. It should be pointed out the data in Figure 1 were measured in the outlet of 3-way catalyst, which is followed downstream by the heat exchanger of EER system. Therefore, based on the exhaust temperate distribution, an appropriate evaporating temperature and mass flow rate would be determined for the working fluids in the thermodynamic cycle of exhaust energy recovery.

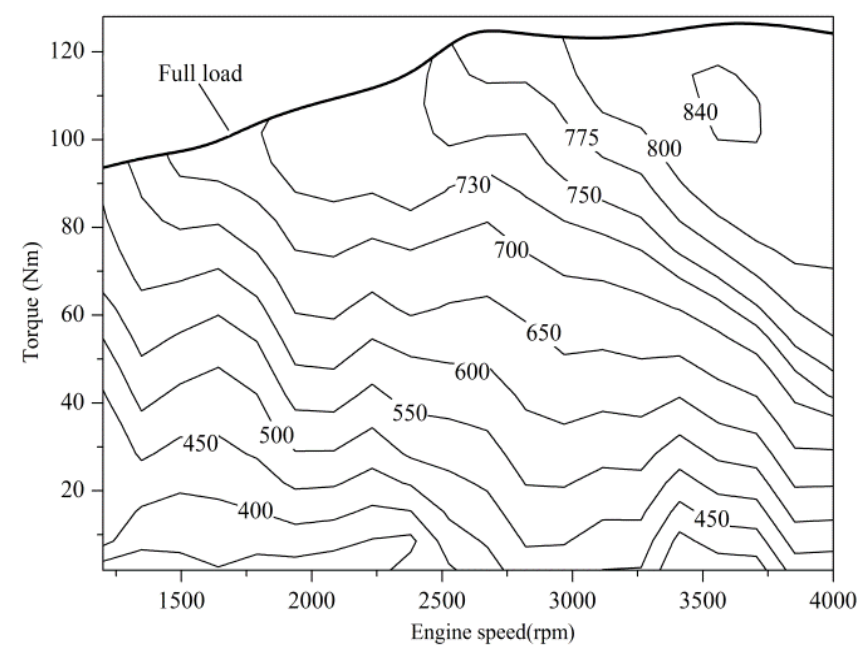

Figure 4 Distribution of exhaust gases temperature of the test engine as function of engine speed and torque

\subsection{Model Validation and Process Parameters}

The role of evaporator is so significant in the EER system because it directly dominates the potential to recover the exhaust energy. Using the above model, the performance of evaporator was 
simulated under various operating conditions. With the recovered efficiency as the efficiency of the evaporator/heat exchanger, the performance of the evaporator can be found in Figure 5.

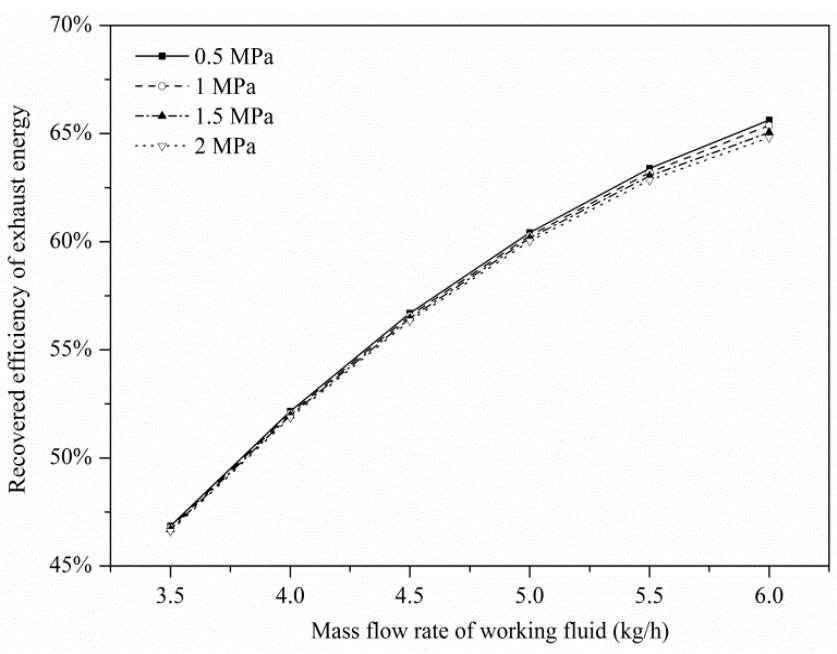

Figure 5 Efficiency of evaporator as function of mass flow rate of working fluid under different evaporating pressure.

From Figure 5, it can be found the efficiency of evaporator depends strongly on the flow rate of working fluid, while it presents a weak dependence on the evaporating pressure.

Based on the present open loop, the calculating model of the EER system was validated. Showed in Figure 6, the experimental and modeling results of the relationship between the working fluid flow rate and pressure are in very good agreement.

\subsection{Fraction of Maximum Recoverable Energy}

After the validation to the modeling method, three kinds of energy efficiencies as defined in Equation 6, Equation 7 and Equation 9 were calculated under different exhaust temperatures and results can be found in Figure 7. 


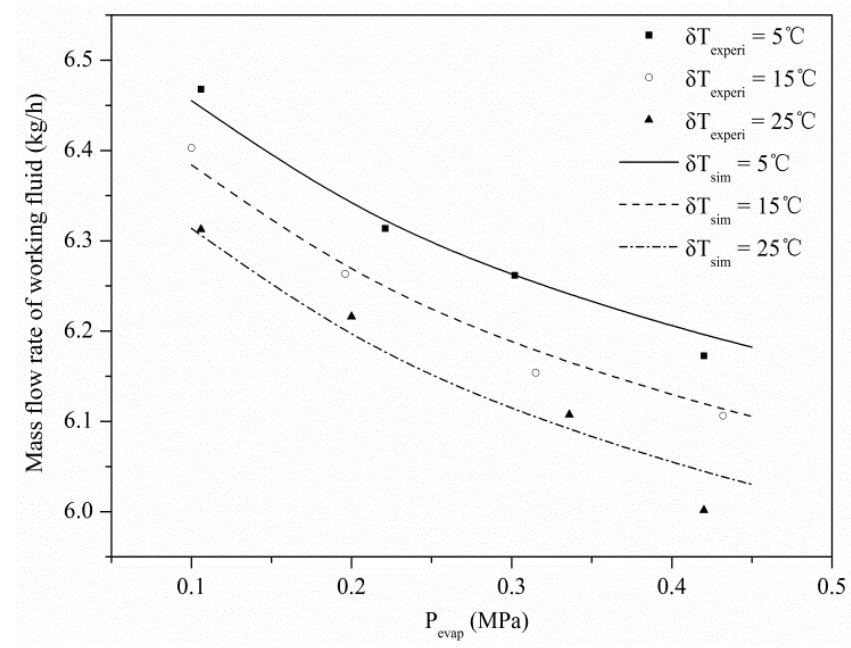

Figure 6 Comparison of experimental and modeling results regarding working fluid mass flow rate under different evaporating pressure ( $\delta \mathrm{T}$ - over-heat degree)

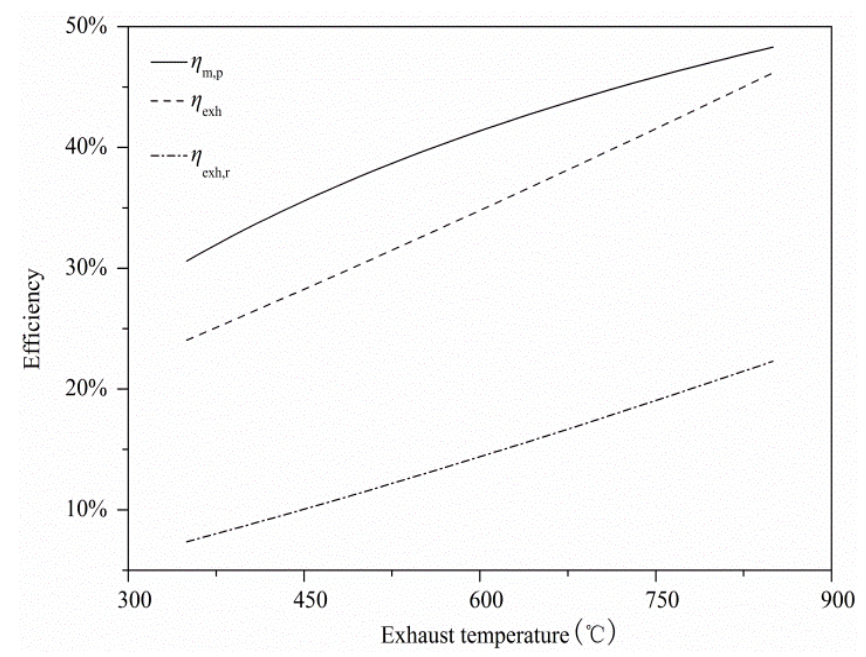

Figure 7 Variation of $\eta_{m, p}, \eta_{e x h}$, and $\eta_{e x h, r}$ as function of the exhaust gases temperature

It could be seen that all three efficiencies present nearly linearity with the exhaust gases temperature. And the fraction of maximum recoverable energy in the total fuel energy $\eta_{\text {exh }, r}$ could exceed $20 \%$ when the temperature is over $800^{\circ} \mathrm{C}$. The temperature characteristics, combined with the distribution 
of exhaust gases temperature, could infer further the optimal conditions that would benefit most to the EER system.

In the real drive cycle of vehicle, the engine speed can range around $2000 \mathrm{rpm}$ to $4000 \mathrm{rpm}$ for most driving conditions. Here, three typical speeds were chosen to demonstrated the variations of the exhaust recoverable efficiency $\eta_{e x h, r}$ with different engine speeds, as presented in Figure 8.

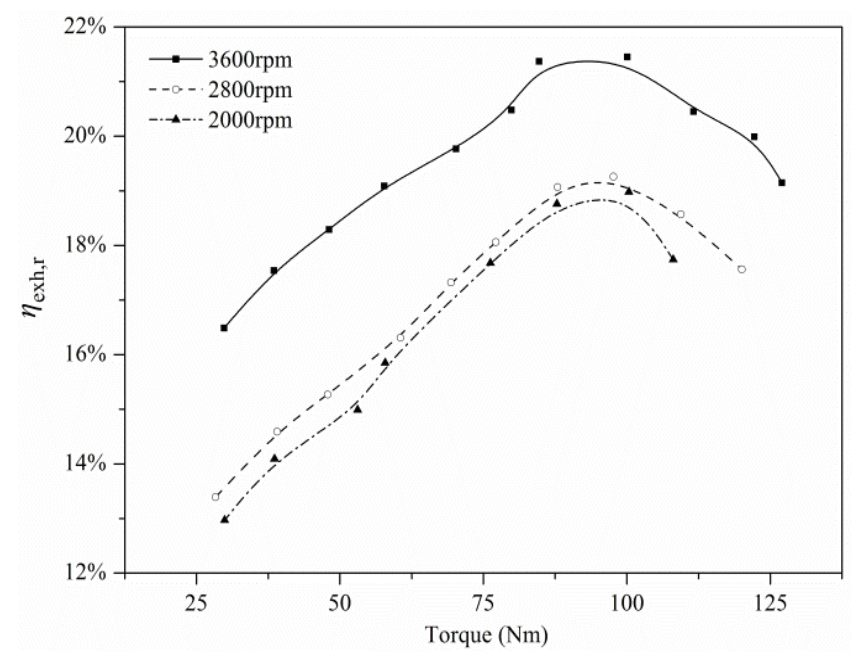

Figure 8 Variations of recoverable exhaust energy efficiency $\eta_{e x h, r}$ with different operating conditions of the test engine

In Figure 8, it could be seen that, given a certain speed, $\eta_{\text {exh,r }}$ increases firstly as the load increases, and reaches up to a maximum when the torques increase among $90 \mathrm{Nm}$ and $100 \mathrm{Nm}$. Then it will decrease if the torques continues to increase further. There exists an optimal operating condition for each engine speed to produce the maximum recoverable exhaust energy. Comparison among the cases in different speeds could make clear that the higher the engine speed, the larger $\eta_{\text {exh,r }}$ will be possible. This could be explained by the fact that the increase of speed would give rise to the increase of the exhaust gases temperature.

Basing on the distribution of the exhaust gases temperature with the engine speeds and loads as shown in Figure 4, the distribution of $\eta_{\text {exh,r }}$ as function of operating conditions could be achieved in 
the same way and the result is presented in Figure 9.

The data in Figure 9 indicates that $\eta_{e x h, r}$ ranges among 0.05 and 0.21 , with a general tendency of proportional increase with speeds and loads. For the speeds among $2000 \mathrm{rpm}$ and $3000 \mathrm{rpm}$, the fraction of maximum recoverable exhaust energy could reach up to $19 \%$ of the total fuel energy at the high loads, while the fraction will become larger in more extensive load scope when the speed is beyond $3000 \mathrm{rpm}$.

As the maximum recoverable exhaust energy represents the maximum recoverable energy of the recovery system, its fraction also gives how much improvements the EER system will contribute to the engine efficiency. Therefore, it could be predicted that the recovery system would operate with a high efficiency in an extensive load scope when the engine speed increases over $3000 \mathrm{rpm}$.

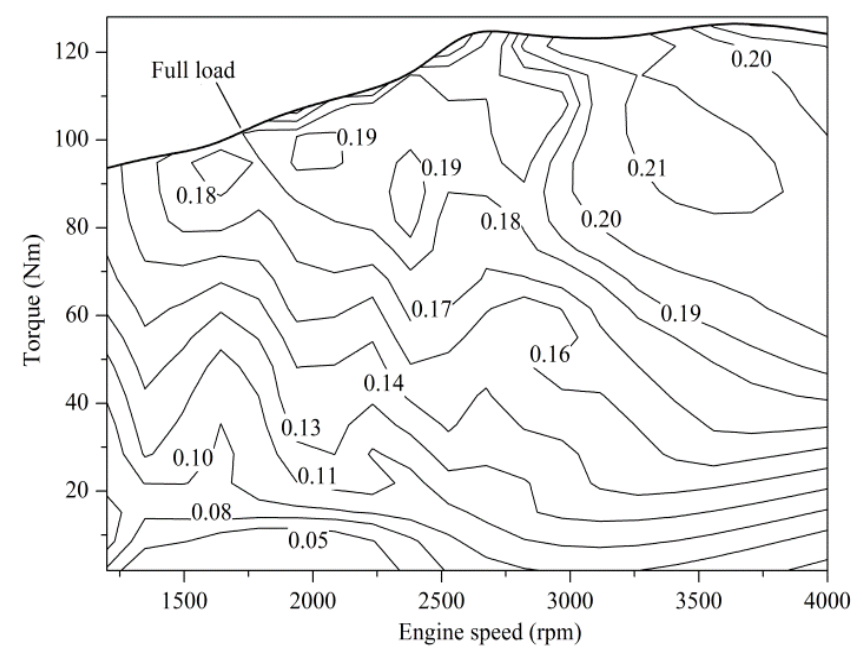

Figure 9 Recoverable exhaust energy efficiency for the test engine as function of the engine speed and torque

\subsection{Influence of the Installation of EER System on Engine Performance}

From those results shown in above section, it has indicated the recoverable exhaust energy efficiency can be around $20 \%$ under some engine operating conditions. This means, a big 
improvement on the engine efficiency can be achieved with EER system. While the above results were produced with the assumption that the EER system would not give any side effect of the exhaust gas flow, it is necessary to find if this is true or not.

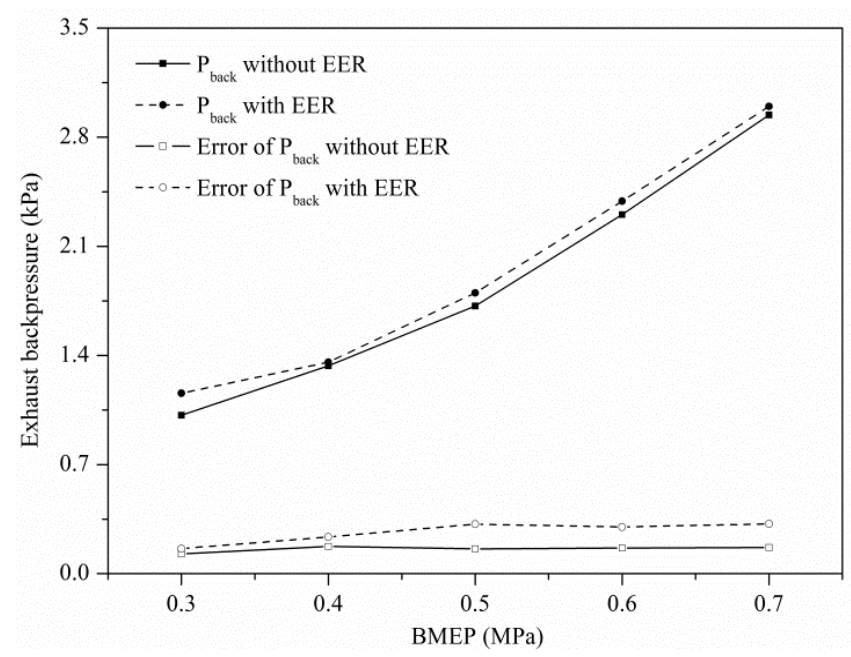

(a)

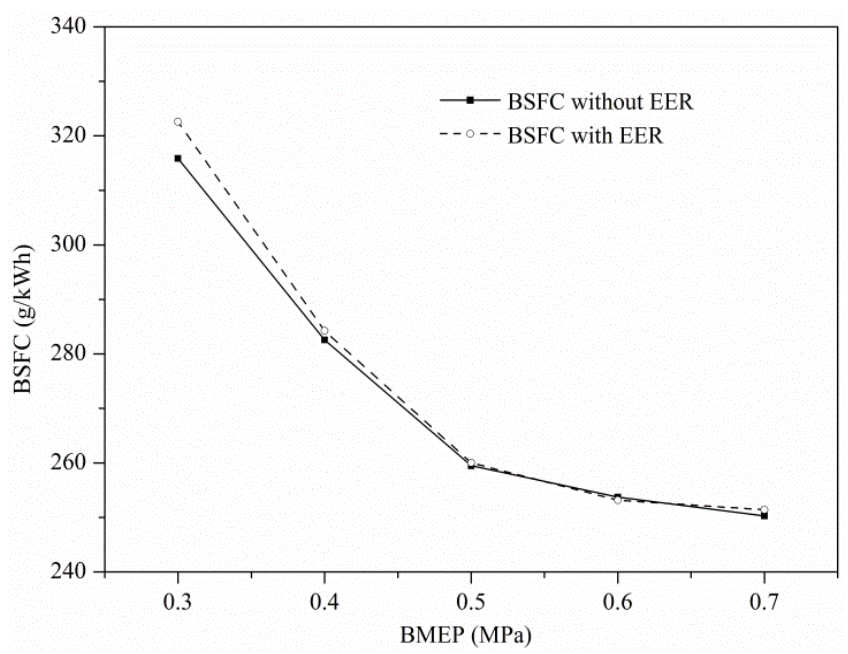

(b)

Figure 10 Influence of EER system on engine: (a) Exhaust back pressure; (b) Brake specific fuel consumption

Shown in Figure 6, the exhaust back pressure and the engine fuel consumption with and without the EER system are presented. It can be found that the exhaust backpressure was increased no more than $0.14 \mathrm{kPa}$ while the specific fuel consumption varied slightly except at $0.3 \mathrm{Mpa}(332.6 \mathrm{vs}$. 315.9, by $5.3 \%$ ). This suggests the present EER system can only increase the exhaust back pressure and the engine fuel consumption with very limited amount. Compared the improvement on the total engine efficiently due to the installation of EER system, the increases (on the exhaust back pressure and the engine fuel consumption) can be ignored.

Following the present test, a new evaporator is under design with aid of CFD for reducing the 
exhaust gas flow resistance further. It is expected the new design will be possible to make the increase of exhaust back pressure very close zero.

\section{CONCLUSIONS}

In the current study, experiments were performed on a light duty gasoline engine for obtaining thermodynamic parameters of exhaust gases under different operating conditions. Based on the experimental data, the exhaust heat and maximum recoverable exhaust energy for an EER (Exhaust Energy Recovery) system based on Rankine Cycle were calculated and analyzed, including the characteristics in terms of temperature and other operating conditions. From those results, the following conclusions can be derived:

- A new parameter, the recoverable exhaust energy efficiency which is actually the fraction of maximum recoverable exhaust energy in the total fuel energy is recommended for reflecting the effects of exhaust temperature and possible exhaust heat on EER efficiency under different engine operating conditions.

- The exhaust gases temperature increases with both of the speed and load in the overall operating conditions of vehicle, ranging among $400^{\circ} \mathrm{C}$ and $850^{\circ} \mathrm{C}$ for the tested light duty gasoline engine. Experimental results of relevant parameters would be beneficial to determining the appropriate evaporating temperature and mass flow rate for the working fluids in the thermodynamic cycle of EER.

- For the EER system installed on the light duty gasoline engine with water as the working fluid, the recoverable exhaust energy efficiency ranges among 5\% and $21 \%$ under different engine operating condition. It tends to increase with engine speed and load. When the speed is beyond $3000 \mathrm{rpm}$, the coefficient could be up to $19 \%$ in a rather wide load range. 


\section{ACKNOWLEDGEMENTS}

Financial supports from the National Basic Research Program of China (973 Program) through the project of 2011CB707201 and the National Natural Science Found of China (NSFC) through the project of 50876074 are gratefully acknowledged.

\section{REFERENCES}

1. Taylor A.M.K.P, Science review of internal combustion engines, Energy Policy. 36 (2008) 4657-4667.

2. Vazaquez J, Zanz-BobiMA, Palacios R, Arenas A. State of the art of thermoelectric generators based on heat recovered from the exhaust gases of automobiles. Proceedings of 7th European workshop on thermoelectrics, 2002.

3. El Chammas, R.G. and D. Clodic, Combined Cycle for Hybrid Vehicles. SAE 2005 World Congress \& Exhibition, 2005. SP-1973 (2005-01-1171).

4. Tianyou Wang, Yajun Zhang, Zhijun Peng, Gequn Shu. A review of researches on thermal exhaust heat recovery with Rankine cycle. Renewable and Sustainable Energy Reviews (2011) 2862-2871.

5. Teng H, Regner G, Cowland C. Achieving high engine efficiency for heavy-duty diesel engines by waste heat recovery using supercritical organic-fluid Rankine cycle. SAE paper 2006-01-3522, 2006

6. Teng H, Regner G, Cowland C. Waste heat recovery of heavy-duty diesel engines by organic Rankine cycle Part I: hybrid energy system of diesel and Rankine engines. SAE paper 2007- 
01-0537, 2007.

7. Teng H, Regner G. Improving fuel economy for HD diesel engines with EHR Rankine cycle driven by EGR cooler heat rejection. SAE paper 2009-01-2913, 2009.

8. Ringler J, Seifert M, Guyotot V, Hübner W. Rankine cycle for waste heat recovery 697 of IC engines. SAE paper 2009-01-0174, 2009.

9. Weerasinghe WMSR, Stobart RK, Hounsham SM. Thermal efficiency improvement in high output diesel engines a comparison of a Rankine cycle with turbo-compounding. Appl Therm Eng 2010,30:2253-6.

10. W.D. Shen, Z.M. Jiang, J.G. Tong, Engineering Thermodynamics, third ed., Higher Education Press, Beijing, 2001.

11. O.M. Ibrahim, S.A. Klein, J.W. Mitchell, Optimum heat power cycles for specified boundary conditions, ASME Journal of Engineering for Gas Turbines and Power. 113 (1991) $514-521$.

12. Jincan Chen, Zijun Yan, Guoxing Lin, Bjarne Andresen, On the Curzon-Ahlborn efficiency and is connection with the efficiency of real heat engines. Energy Conversion \& Management 42 (2001) $173 \pm 181$.

13. S.A. Klein, An explanation for observed compression ratios in internal combustion engines, ASME Journal of Engineering for Gas Turbines and Power. 113 (1990) 511-513.

14. J. Ringler, M. Seifert, V. Guyotot, W. Hübner, Rankine cycle for waste heat recovery of IC engines, SAE paper 2009-01-0174. 